\title{
Project Scheduling Management in the Software Industry
}

\section{Rozi Nor Haizan Nor'*, Yusmadi Yah Jusoh², Farihan Che Mohamed ${ }^{3}$, Sawalrudin Abu Hassan ${ }^{4}$, Mohd Fahmi Mohd Shari ${ }^{5}$}

${ }_{1,2,3,4,5}$ Department of Software Engineering and Information Systems,

Faculty of Computer Science and Information Technology, Universiti Putra Malaysia,

UPM Serdang, Selangor, Malaysia

rozinor@upm.edu.my*1

Article History: Received: 10 November 2020; Revised: 12 January 2021; Accepted: 27 January 2021; Published online: 05 April 2021

\begin{abstract}
Project scheduling is the next step once project planning is completed. This requires knowledge and the depth of the activities, the dependencies between activities and, duration of the activities. Creating and designing a realistic project schedule is the biggest challenges a project manager faces. There are some common problems that can be impact towards project delay or performance: Assigning Resource or Resource Constraint, Managing the Unknown or Managing Change and Estimating Task Duration. These 3 factors and causes are contributing to project scheduling problem. The impact of resource constraint causes towards be impact towards project delay or performance. To achieve this goal, the survey has been conducted. Finally, the results of the surveys are presented in order to see which commons problems are the most happening and really effected project scheduling.
\end{abstract}

Keywords: Project scheduling; Project planning; Performance

\section{Introduction}

Software project scheduling problems can be classified considering various factors such as the amount of stages in the job process, the number of machines present for each stage, different job processing requirements, setup time/cost requirements and the performance measure to be optimized. This scheduling problem is used to organize many activities that require various resources; these resources may or may not be renewable and comply with the objectives set out above. Unless the project that we need to schedule is similar to a previous one, this is one of the most difficult tasks that project managers have to face. This scheduling problem consists of assigning a set of tasks to a set of employees, thus introducing the difficulty of each employee possessing the skills necessary to complete this task. The allocation must meet the requirement that a project incurs minimal cost and is completed in the least amount of time. The project scheduling activity consists in dividing the total project into a series of activities, which may be performed in parallel, and estimating the necessary time for each of them. In this paper, project scheduling problem and its categorization are evaluated from various aspects.

\section{Literature Review}

\subsection{Resource Constrained Project Scheduling Problem (RCPSP)}

The Resource Constrained Project Scheduling Problem (RCPSP) is the sub-class of the Scheduling Problem that deals with scenarios where personnel or workforce employed to perform the tasks are limited and each job has an arrival time, a due date, and a penalty associated to delays. Activities cannot be completed on time because some resources such as manpower, material are not available at that time. Gnagi, Rihm, Zimmermann and Trautmann (2019) have identified three different types of the consumption resources depends on the nature of that activity which is renewable, non-renewable and doubly constrained resources:

- Renewable resources, e.g., manpower

- For non-renewable resources, e.g., raw materials

- Doubly constrained resources

\subsection{Managing Unknown or Managing Change}

Bordley, Keisler, and Logan (2019) has proposed a much more easily implemented approach to incorporating deadline uncertainty into managerial decision making which makes no changes to conventional project management procedures. But in reality, project deadlines frequently change. Conventional project management addresses unanticipated changes in the project deadline with external change control processes. If this external process changes the deadline, the manager will replace the original deadline with the modified deadline.

\subsection{Estimating Task Duration}


Choi and Kang (2015) stated that this technique is used in many studies related to project scheduling, as well as especially the researches in which there is a trade-off between time and cost. In addition, a high limit for the number of pre-emption in one activity and a maximum duration as limitation for duration between the interruption and restart of the activity were defined.In some conditions, it is necessary to minimize the duration between the completion time and deadline of activities. This type of scheduling is recognized as earlinesstardiness project scheduling problem.

\section{Materials And Methods}

The objective of this paper is to present the current practices on the software projects scheduling in Malaysia. In order to capture the software projects scheduling experiences of ICT officers from the various sectors in Malaysia, an exploratory research was carried out. ICT officers are the people who manage and deliver software projects at Malaysian Public Sector, Private Sector and Semi-Private company. Thus, a survey questionnaire was designed in order to get a response from these officers.

The aim of this survey is to investigate the current practices and problems on software project scheduling at Malaysian Public, Private and Semi-Private Sector.The questions in this questionnaire is divided into three sections. The first section is to collect demography of respondents from various sectors. The second section is to identify the current practices on software projects scheduling at Malaysian Public, Private and Semi-Private Sector. Then followed by the third section is to investigate the software project scheduling problem experience by respondents.

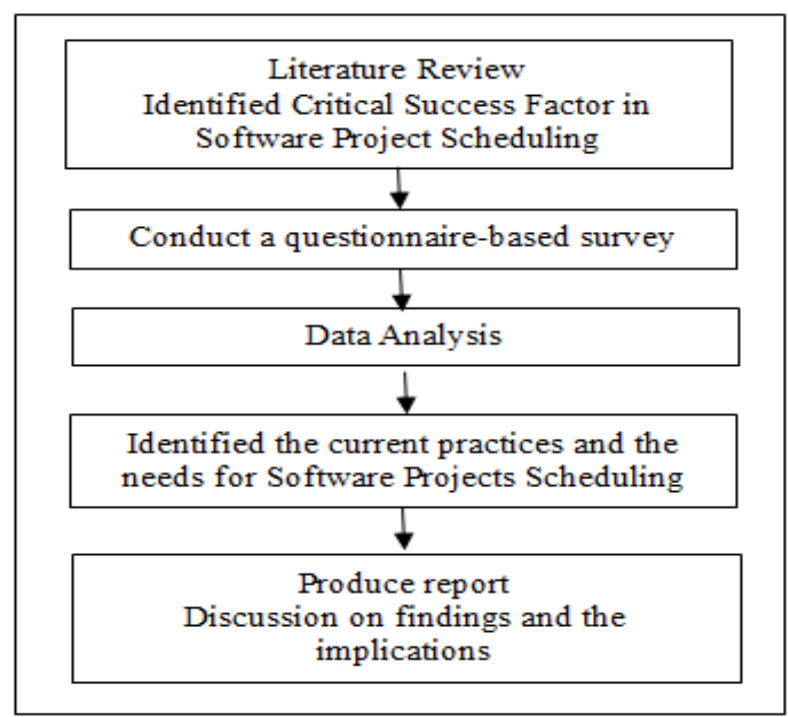

Figure 1.Research Framework

Figure 1 shows the activities that performed in this research. The activity starts from literature review and continued with survey conduction. The next activity is data analysis. Data are collected and analysed with basic statistic techniques similar to Hussain at el., (2016). Based on this analysis, the needs for software projects scheduling is identified and finally produce a report that discussed about the findings and its implication to ICT in Malaysian Software Industry.

\section{Results and Discussion}

The findings from this survey are analyzed into three sections. They are demography respondents, current practices on software projects scheduling and software projects scheduling problems. The survey questionnaire was distributed randomly to the targeted respondents that represent various public sector, private sector and semi-private company in Malaysia. A web-based survey was conducted to collect data. A total of 120 survey questionnaires were obtained over a period of 3 weeks from the respondents and all 120 questionnaire surveys were used for this study.

\subsection{Demography of Respondents}


Respondents who took parts in this survey are analyzed in term of their gender, the age, and the marital status, and current position, number of year's work experience, the company sector and the type of industry they are attached currently. These seven variables are chosen in order to address the correct respondents for this undertaken survey. By knowing the company sector they attached currently, we could identify in which agency type needed monitoring processes.

Table 1.Demography Information of Survey Respondents

\begin{tabular}{|c|c|}
\hline 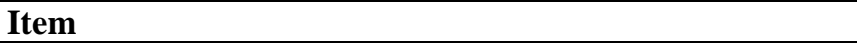 & Rate \\
\hline Gender & \\
\hline Male & $45 \%$ \\
\hline Female & $55 \%$ \\
\hline Age & \\
\hline $36-45$ & $40 \%$ \\
\hline $25-35$ & $40 \%$ \\
\hline $18-25$ & $15 \%$ \\
\hline More than 45 & $5 \%$ \\
\hline Marital Status & \\
\hline Married & $56.7 \%$ \\
\hline Single & $43.3 \%$ \\
\hline Current Position & \\
\hline Project Manager & $16.7 \%$ \\
\hline Business Analyst & $13.3 \%$ \\
\hline Software Developer & $20.8 \%$ \\
\hline Tester & $6.7 \%$ \\
\hline Others:(Operational, Director) & $42.5 \%$ \\
\hline $\begin{array}{l}\text { Number of years involvement in software project } \\
\text { development }\end{array}$ & 1 - more than 10 years \\
\hline Company Sector & \\
\hline Public Sector & $51.7 \%$ \\
\hline Private Sector & $37.5 \%$ \\
\hline Semi-Private Company & $7.5 \%$ \\
\hline Company Industry & \\
\hline Information Technology & $60.8 \%$ \\
\hline Education & $15.8 \%$ \\
\hline Telecommunication & $9.2 \%$ \\
\hline Banking & $5.8 \%$ \\
\hline Others:(Healthcare,Construction etc) & $8.4 \%$ \\
\hline
\end{tabular}

Table 1 provides demography details of the respondents who participate in this study. Majority of these respondents $(50.8 \%)$ are holding working title as software developer / programmer and followed by project manager and business analyst. This shows that this survey reaches to the exact people who are dealing with software projects management in Malaysia. Moreover, the respondents have working experiences from 1 to more than 10 years. Thus, this survey response reflects the actual situations of software projects development in Malaysia. These findings could lead to further enhancement on the current practices. Since most the software projects development is dealt by government, thus this survey finding is very reliable and meaningful too in order to represent the actual situations in the Malaysia in terms of neither software projects development nor software projects monitoring.

\subsection{Current practices on software projects scheduling}

The main objective of this research is to identify the current practices on software project scheduling of software projects development in Malaysia. This research is a preliminary work in order to cater information on current project scheduling The Table 2 below shows the current practices on the software projects development and software projects scheduling in Malaysia. From this survey, we have identified that the majority of respondents have experience involving more than 5 projects $(33.3 \%)$ while $25 \%$ are involved in 3 software projects. This survey also described how long the duration of the software project. Project scheduling tools are a great way to get project more organized, providing the whole team with a platform where they can collaborate 
and many other benefits. This study shows that from $90 \%$ response only $12.5 \%$ that always use scheduling software. This rate is relatively low and needs to be improved. The parties involved may take action on this matter.

Table 2.Software Project Development and Software Project Scheduling in Malaysia

\begin{tabular}{|l|l|}
\hline Item & Rate \\
\hline Number of projects involve: & \\
More than 5 & $33.3 \%$ \\
5 & $6.7 \%$ \\
4 & $10.8 \%$ \\
3 & $25 \%$ \\
2 & $13.3 \%$ \\
1 & $10.8 \%$ \\
\hline Duration of the project: & \\
More than 12 months & \\
Between 6 to 12 months & $22.5 \%$ \\
Below than 6 months & $51.7 \%$ \\
Others: (Not Specified) & $22.5 \%$ \\
\hline Number of manpower involve in 1 project: & $3.3 \%$ \\
Below than 5 & \\
Between 5 to 10 & \\
Between 11 to 20 & $30.8 \%$ \\
More than 20 & $45.8 \%$ \\
Others: (Not Specified) & $11.7 \%$ \\
& $8.4 \%$ \\
\hline Method used in project scheduling: & $3.3 \%$ \\
Program Evaluation Review Technique (PERT) & \\
Critical Path Method (CPM) & \\
Work-Breakdown Structure (WBS) & $25 \%$ \\
Expert Judgment & $21.7 \%$ \\
Comparative or Analogous Estimation & $20.8 \%$ \\
Others: (Parametric Model Estimating etc) & $16.7 \%$ \\
\hline Use of any software application for project scheduling: & $9.2 \%$ \\
Never & $6.6 \%$ \\
Rarely & \\
Sometimes & $10 \%$ \\
Always & $12.5 \%$ \\
\hline
\end{tabular}

\subsection{Software projects scheduling problems}

Based on the literature review, we had identified three main problems in software project scheduling that can be impact towards project delay/performance. Those three main problems are: assigning resource/resource constraint; managing the unknown/managing change; and estimating task duration. The Table 3 below shows the identified three problems through this survey. From this survey, the first problem related to assigning resource/ resource constraint that could impact the delay/performance of the project is that $87 \%$ of respondents agree. For second problem related to managing the unknown / managing change causes' that could impact on the project delay / performance, we identified 9 factors that could cause to the impact. For the third problems related to estimating task duration causes' that can impact on the project delay/performance, we identified 7 factors that could cause to this impact. By having an effective project scheduling, it will increase project productivity and efficiency. A good project scheduling helps team to stay on track to get important projects done, then we could produce more successful software projects.

Table 3. Software Project Scheduling Problems in Malaysia

\begin{tabular}{|l|l}
\hline Factor/Cause & Rate
\end{tabular}




\begin{tabular}{|c|c|}
\hline $\begin{array}{l}\text { Resource constraint causes can impact on the project delay / } \\
\text { performance }\end{array}$ & $87 \%$ \\
\hline $\begin{array}{l}\text { Managing the unknown / managing change causes' that can } \\
\text { impact on the project delay / performance } \\
\text { i. Change in business environment } \\
\text { ii. Problem with new technology } \\
\text { iii. Identifying possible risks at the beginning of the project } \\
\text { iv. Changes to the scope of the project } \\
\text { v. Changes not go through a formal project change management } \\
\text { process } \\
\text { vi. Requirements change because of unforeseen changes in } \\
\text { stakeholder needs } \\
\text { vii. Certain activities either fail to achieve or over-achieve their } \\
\text { requirements } \\
\text { viii. Organizational politics } \\
\text { ix. Price change }\end{array}$ & $\begin{array}{l}90.9 \% \\
90.9 \% \\
91.7 \% \\
92.5 \% \\
89.2 \% \\
93.3 \% \\
94.1 \% \\
93.3 \% \\
90.8 \%\end{array}$ \\
\hline $\begin{array}{l}\text { Estimating task duration causes' that can impact on the project } \\
\text { delay / performance } \\
\text { i. Constant Changes In The Project's Scope } \\
\text { ii. Inappropriate and Inadequate Procurement } \\
\text { iii. Complexity of Project } \\
\text { iv. Post Execution Phase (Closure) } \\
\text { v. Underestimate how long the task will take them to do } \\
\text { vi. Overlook/miss any necessary project tasks } \\
\text { vii. Actual work activity duration gets changed due to unexpected } \\
\text { things }\end{array}$ & $\begin{array}{l}93.3 \% \\
96.6 \% \\
94.2 \% \\
96.6 \% \\
94.1 \% \\
95.0 \% \\
95.8 \%\end{array}$ \\
\hline
\end{tabular}

\section{Conclusion}

The findings through this survey revealed that current practices on software projects scheduling and software projects scheduling problems effected to the success of projects development. Based on the result, we believe that software project scheduling is needed and can be an important consideration factor to Malaysian Public Sector, Private Sector and Semi-Private Company in order to manage and control the software projects development processes towards to its success.

\section{References}

1. Bordley, R. F., Keisler, J. M., and Logan, T. M. (2019). Managing projects with uncertain deadlines. $\begin{array}{lllll}\text { European Journal of 291-302. } & \text { Operational Research, 274(1). 20 }\end{array}$ https://www.sciencedirect.com/science/article/abs/pii/S0377221718308130

2. Cavalcante, Cristina, C. C. Carvalho, D. S., Martin, W. S., Yaoguang, W., and Laurence, A. W. (2001). Scheduling projects with labor constraints. Discrete Applied Mathematics 112, no. 1-3. 27-52. https://www.sciencedirect.com/science/article/pii/S0166218X00003085

3. Choi, S. H., and Kang, Y. C. (2015). Sodium ion storage properties of WS 2-decorated threedimensional reduced graphene oxide microspheres. Nanoscale, 7(9), 3965-3970. https://pubs.rsc.org/en/content/articlelanding/2015/nr/c4nr06880g/unauth\#!divAbstract

4. Gnägi, M., Rihm, T., Zimmermann, A., and Trautmann, N. (2019). Two continuous-time assignmentbased models for the multi-mode resource-constrained project scheduling problem. Computers \& $\begin{array}{lll}\text { industrial } & \text { engineering, } & 129 .\end{array}$ https://www.sciencedirect.com/science/article/abs/pii/S0360835219300373

5. Hussain, A., Mkpojiogu, E.O.C., Yusof, M.M. (2016). The effect of proposed software products' features on the satisfaction and dissatisfaction of potential customers. AIP Conference Proceedings, 1761 , art. no. 020052. 
6. Wang, M. Y., Siddiqi, M. Y., Ruth, T. J., and Glass, A. D. (1993). Ammonium uptake by rice roots (II. Kinetics of 13NH4+ influx across the plasmalemma). Plant physiology, 103(4), 1259-1267. http://www.plantphysiol.org/content/103/4/1259.short

7. Xiao, J. P., He, J. F., Deng, A. P., Lin, H. L., Song, T., Peng, Z. Q., Wu, X. C., Liu, T., Li, Z. H., Rutherford, S. and Zeng, W. L. (2016). Characterizing a large outbreak of dengue fever in Guangdong Province, China. Infectious diseases of poverty, 44. https://idpjournal.biomedcentral.com/articles/10.1186/s40249-016-0131-z

8. Xiao, Y., Liu, H., Chen, Y., and Jiang, J. (2014). Bounding surface plasticity model incorporating the state pressure index for rockfill materials. Journal of Engineering Mechanics, 140(11). https://ascelibrary.org/doi/abs/10.1061/(ASCE)EM.1943-7889.0000802 